This is the Accepted Manuscript of an article published online by Taylor \& Francis in "Road Materials and Pavement Design" on 01 December 2017, available online: https://www.tandfonline.com/doi/full/10.1080/14680629.2017.1407818 


\title{
Experimental application of waste glass powder filler in recycled dense-graded asphalt mixtures
}

\author{
Andrea Simone, Francesco Mazzotta*, Shahin Eskandarsefat, Cesare Sangiorgi, Valeria Vignali, \\ Claudio Lantieri and Giulio Dondi
}

DICAM Department, School of Engineering and Architecture, University of Bologna, Bologna, Italy

*Corresponding author.Email:francesco.mazzotta2@unibo.it

\begin{abstract}
This paper presents laboratory study results, including both bituminous mastics and mixtures tests, to assess the use of glass powder (GP) as possible surrogate to limestone filler in recycled dense-graded asphalt mixtures. To achieve a comprehensive approach, the analysis has been divided into three parts including filler, mastics and mixture characterisation. The GP has been completely studied with chemical and physical tests to compare the fundamental characteristics to the commonly used limestone filler. In the second part, rheological tests using the Dynamic Shear Rheometer has been implemented to evaluate fillers interaction with not modified and modified bitumen. Finally, the mechanical properties of the asphalt mixtures containing GP filler were investigated in terms of indirect tensile strength, indirect tensile stiffness modulus and creep characteristics. According to the obtained results, GP filler provided comparable values to limestone filler within both mastic and mixture study. It is noteworthy that from the permanent deformation analysis, both MSCR and RLAT tests confirmed the improvement of rutting resistance with using GP filler.
\end{abstract}

Keywords: road pavements; glass powder; recycling; asphalt mixture; rheology

\section{Introduction}

In order to minimise the environmental impacts of roads construction and maintenance, it is necessary to quantify the energy and resources savings. In particular, based on the European Green Public Procurement (GPP), criteria for road design are now crucial to provide a minimum requirement regarding to the amount of recycled content in road elements. In this context, the validity of sustainable construction focused on using recycled materials (Mazzotta et al., 2017; Vignali et al., 2016) becomes fundamental in terms of life cycle assessment (LCA) of road infrastructures. In the last decade, besides the environmental aspects, the high economic pressure of virgin material cost and the limited resources have obliged the decision-makers to use recycled materials more than before. Reclaimed asphalt pavement (RAP), recycled asphalt shingles (RAS), waste plastics and grind (and/or powdered) glass are some of the investigated materials in the pavement industry. While the objectives of RAP and RAS incorporation in asphalt mixtures are reusing both aggregate and binder, the waste powders such as waste brick (Arabani, Tahami, \& Taghipoor, 2016), waste bleaching clay (Mazzotta, Sangiorgi, Vignali, Lantieri, \& Dondi, 2015; Sangiorgi et al., 2016a), rice husk ash (Al-Hdabi, 2016) and glass powder (GP) were investigated to substitute the traditional limestone filler. In this regard, many studies have 
shown the influence of filler type on the rheo-mechanical behaviour of bituminous mixtures (Anderson et al., 2001; Kim, Allen, \& Little, 2007).

Among the studied materials, waste glass has been investigated as a portion of virgin aggregates in many previous researches. These studies have shown that the low absorption properties of glass particles play a key role for further performance deficiencies (Ghasemi \& Marandi, 2013). The early stripping, high ravelling potential and reduced skid resistance are some of the main problems due to low porosity of glass particles, which led to use glass as an alternative filler or fine aggregates (Kandhal, 1996; Wu, Yang, \& Xue, 2007). The nature of mineral aggregates is one of the main factors that influences both cohesion and adhesion properties (Lamperti, Grenfell, Sangiorgi, Lantieri, \& Airey, 2016).

Considering the GP as filler, several researchers found that the use of recycled GP does not worsen mechanical and performance properties of asphalt mixtures. For instance, it is indicated that replacement of limestone filler by GP resulted in lower flow rate and higher stability (Flynn, 1993; Jony, Al-Rubaie, \& Jahad, 2011). However, in contrast, another research showed that the replacement of limestone filler by GP increases the flow rate and decreases the stability (Saffar, 2013). Further studies proved that GP has an effective role in moisture susceptibility and resilient modulus of conventional asphalt mixtures (Wu et al., 2007). In literature, there is agreement for volumetric analysis of the mixtures containing GP. Many previous researches showed that the substitution of mineral filler by GP will result in lower density and higher air voids. The logical explanation for this goes to lower adsorption and chemical exchange between silica and asphalt, which makes more free binder in the mixture (Tang, Wu, Liao, \& Huang, 2015). In this research, the GP filler, probably due the low mastic percentage in the studied mixtures, does not influence a lot the stability. The increase of mastic matrix in the volume of the mixture, typical of an SMA, has a proportional effect on the stability results of the GP filler mixture if you compare it with the control mixture using limestone filler (Udaya \& Venkateswara, 2016).

Starting from the review of the available literature of GP filler application, a lack of rheological characterisation of bitumen and mastics has been verified. The aim of the current study is to assess the applicability of GP as an alternative to commonly used limestone filler. The presented experimental work mainly included three parts, including GP prequalification assessments, rheological analysis on mastics made with GP and limestone, and asphalt mixture mechanical evaluation with static and dynamic tests.

\section{Materials}

Figure 1 shows the studied materials in view of a multi-scale approach for the eight different combination of fillers and bitumens. In particular, the research have been started by filler characterisation, followed by mastic rheological studies and concluded with an analysis of mixture properties. Therefore, after defining the mix design, fillers and mastics that compose the asphalt mixture have been studied. The products obtained with the use of GP were compared with the corresponding ones containing limestone filler. In order to provide a comprehensive knowledge on the applicability of using the same design, neat and modified bitumen were used. Table 1 shows the composition of the studied mastics and mixtures using both neat and modified bitumen:

\section{Aggregates}

The aggregates used in the current experimental work were $80 \%$ of virgin crushed limestone and $20 \%$ of RAP. The selected gradation of aggregates is shown in Figure 2. The choice of grain size was based on the one of the typical Italian specifications (ANAS) gradation limits of HMA mixtures for surface layers. The volumetric mass of the aggregates was calculated according to the EN 1097-6 standard. 




Figure 1. Materials and experimental plan.

Table 1. Filler and binder content. Asphalt mixture samples and mastics.

\begin{tabular}{lcccc}
\hline Scale & GP filler $(\%)$ & $\begin{array}{c}\text { Limestone filler } \\
(\%)\end{array}$ & $\begin{array}{c}\text { Bitumen }(\% \text { on weight } \\
\text { of aggregate })\end{array}$ & Mixture ID \\
\hline Asphalt mixture & 7 & - & 5.5 & GP-NB GP-PmB \\
Mastic & 66 & - & 44 & GP-NB GP-PmB \\
Asphalt mixture & - & 7 & 5.5 & LS-NB LS-PmB \\
Mastic & - & 66 & 44 & LS-NB LS-PmB \\
\hline
\end{tabular}

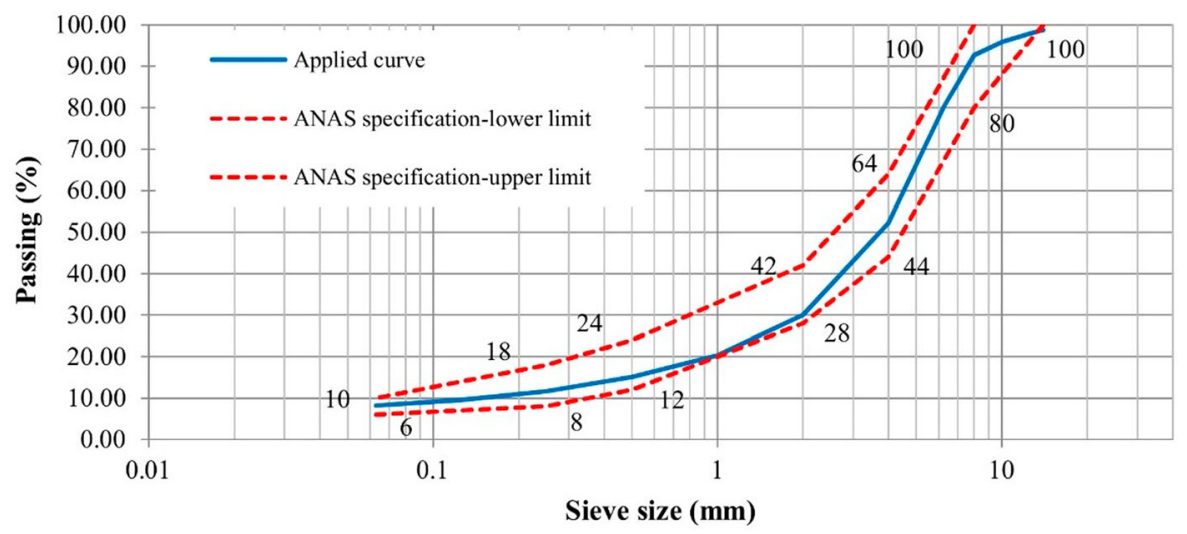

Figure 2. Applied aggregate gradation (ANAS, Italian specifications).

\section{Limestone filler}

The used limestone filler properties complied with the following requirements:

- Calcium carbonate content $\geq 75 \%$ by mass (typically $\mathrm{CaCO}_{3} \approx 95 \%$ );

- Clay content (adsorption of methylene blue) $\leq 1.20 \mathrm{~g} / 100 \mathrm{~g}$;

- Organic content $(\mathrm{TOC}) \leq 0.20 \%$ by mass (for the type $\mathrm{LL} \leq 0.50 \%$ by mass, $\mathrm{FeO}_{2} \approx 0.2 \%$ to $\mathrm{SiO}_{2} \approx 0.4 \%$. 



Figure 3. GP before and after drying process.

Table 2. GP chemical components.

\begin{tabular}{lc}
\hline Chemical component & Content (\%) \\
\hline $\mathrm{SiO}_{2}$ & 29.17 \\
$\mathrm{CaO}$ & 16.51 \\
$\mathrm{Al}_{2} \mathrm{O}_{3}$ & 18.85 \\
$\mathrm{Fe}_{2} \mathrm{O}_{3}$ & 6.97 \\
$\mathrm{MgO}$ & 2.60 \\
$\mathrm{Na}_{2} \mathrm{O}$ & 10.72 \\
$\mathrm{~K}_{2} \mathrm{O}$ & 0.65 \\
$\mathrm{SO}_{3}$ & 0.87 \\
$\mathrm{CaCO}_{3}$ & - \\
other & 13.66 \\
\hline
\end{tabular}

\section{GP filler}

Recycled GP is an innovative, eco-friendly and multifunctional filler coming from the processing residual of goldsmith industries. Before grinding, the waste is subjected to iron and plasticisation removal processes. Later it is send to the crusher, which imparts a first crushing to the material, reducing the size to not more than $2 \mathrm{~mm}$. Subsequently, the filler is sent directly to a rotary mill, which reduces the size to less than $75 \mu \mathrm{m}$. Through a system of sieves or with a classifier, the turbine material is checked and calibrated. At this point, the material undergoes the washing operation because of the high dustiness possessed by the material. Chemical properties of the studied GP are provided in Table 2. As shown, the GP filler has a low content of silica $\mathrm{SiO}_{2}$ (about 30\%), although it is the main constituent. Calcium oxide $(\mathrm{CaO})$, alumina $\left(\mathrm{Al}_{2} \mathrm{O}_{3}\right)$ and sodium oxide $\left(\mathrm{Na}_{2} \mathrm{O}\right)$ are present inside the compound in a percentage ranging between $10 \%$ and $19 \%$. The percentages of the other oxides are less than $1 \%$. Considering the chemical analysis, it can be stated that the source of recycled glass is various, which implies that this material has not been subjected to a special refining processes, making this a cheaper and environmentally friendly product. The wet GP is similar to a mud with graybrown clay colour. Once dried turns out to be a fine powder of texture and colour similar to ash (Figure 3). 
Table 3. GP filler vs. limestone filler characteristics.

\begin{tabular}{lccccc}
\hline Filler ID & $\begin{array}{c}\text { Volumetric } \\
\text { mass }\left(\mathrm{mg} / \mathrm{m}^{3}\right)\end{array}$ & $\begin{array}{c}\text { Rigden voids } \\
(\%)\end{array}$ & $\begin{array}{c}\text { Blue of } \\
\text { methylene } \\
\left(\mathrm{g}_{\text {blu }} / \mathrm{kg}_{\text {filler }}\right)\end{array}$ & $\begin{array}{c}\text { Water solubility } \\
(\%)\end{array}$ & $\begin{array}{c}\text { Delta Ring } \\
\text { \& Ball }\left({ }^{\circ} \mathrm{C}\right)\end{array}$ \\
\hline GP filler & 2.47 & 28.67 & 5.0 & 2.0 & 10.20 \\
Limestone filler & 2.55 & 35.40 & 1.2 & 0.2 & 7.50 \\
\hline
\end{tabular}

In order to use GP as the filler in asphalt mixtures, it has been completely dried and later been characterised with the following tests described below (Figure 4):

- Particle size analysis was conducted with the photo sedimentation process (Micrometrics SediGraph 5100) for the fraction between 0.5 and $100 \mu \mathrm{m}$, and through wet sieving for the portion greater than $100 \mu \mathrm{m}$.

- The Rigden void test (EN 1097-4) was performed to determine the void volume in the drycompacted fillers. It is based on the assumption that the maximum bulk density of fines can be obtained by compacting the dry fines in a mould (Figure 4).

- The specific bulk density test (EN 1097-7) was carried out to determine the specific bulk gravity of the filler, using standardised pycnometers.

- The blue of methylene test (EN 933-9) was performed to determine the amount of methylene blue adsorbed by GP. The result is reported as a methylene blue value in units of (mg) of methylene blue adsorbed per $(\mathrm{g})$ of fine filler. The methylene blue value is a function of the amount and of characteristics of clay minerals present in the specimen. High methylene blue values indicate increased potential for reduced fine aggregate or mineral filler performance in aggregates mixture due to the presence of clay (Figure 4).

- The water sensitivity test (EN 1744-1) was performed to evaluate filler solubility resistance in water (Figure 4).

- The Delta Ring and Ball test (EN 13179-1) was implemented to assess the stiffening effect of mineral fillers used in asphalt mixtures.

- GP and limestone filler particle size analysis results are reported in Figure 5; the GP is clearly finer than the limestone filler.

In Table 3, GP characteristics are compared with traditional limestone filler ones. Rigden voids test provides information about the potential amount of bitumen that the filler can adsorb and, as a consequence, is an indicator of the stiffening power that the filler exercises on the bituminous mastic (Sangiorgi et al., 2017). According to the EN 13043 standard, the values of the Rigden Voids are restricted to the interval 28-55\%. Taking this standard as reference, the GP filler respects the defined limits. About the methylene blue, it can be stated than the presence of the fine part is higher in GP filler than limestone; however, both filler respects the standard limits. The EN 13043 standard suggests that the limit value of solubility in water is $10 \%$. The water solubility for the GP filler is close to the value obtained for the limestone one and Delta Ring \& Ball values close to $10^{\circ} \mathrm{C}$ guarantees a good workability of the mixtures.

\section{Binders}

For this research, one SBS-modified bitumen and a commonly used 50/70 pen-graded neat bitumen were used producing in both asphalt mixtures specimens and mastics samples. It is worth mentioning that the SBS polymer-modified bitumen ( $3 \%$ in weight of bitumen) has been 


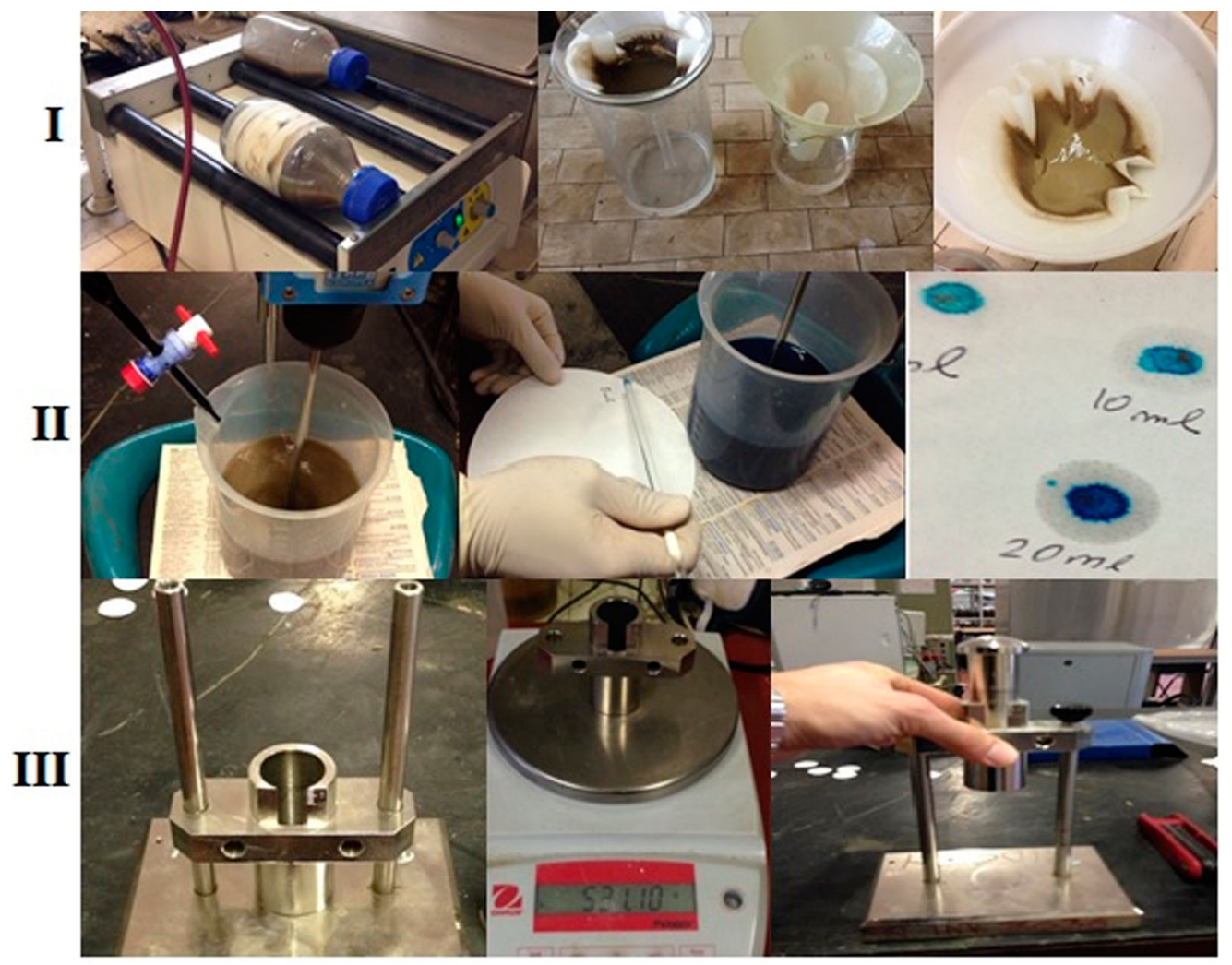

Figure 4. GP filler characterisation tests; (I) Water sensitivity test EN 1744-1, (II) Blu of Methylene test EN 933-9, and (III) Rigden Void EN 1097-4.



Figure 5. GP gradation vs. limestone particle grading. 
Table 4. Physical properties of the binders.

\begin{tabular}{llccc}
\hline & & \multicolumn{2}{c}{ Bitumen type } \\
\cline { 2 - 4 } Property & Unit & Pen grade 50/70 & PmB (SBS) & Standard \\
\hline Penetration @ $25^{\circ} \mathrm{C}$ & $\mathrm{dmm}$ & 50 & 55 & EN 1426 \\
Softening Point & ${ }^{\circ} \mathrm{C}$ & 50 & 70 & EN 1427 \\
Force Ductility test @ $10^{\circ} \mathrm{C}$ & $\mathrm{J} / \mathrm{cm}^{3}$ & - & 3 & EN 13589 \\
Dynamic Viscosity @ $160^{\circ} \mathrm{C}$ & $\mathrm{Pa} \mathrm{s}$ & 0.5 & 0.7 & EN 12596 \\
Elastic Recovery @ $25^{\circ} \mathrm{C}$ & $\%$ & - & 80 & EN 13398 \\
\hline
\end{tabular}

described as type P by Dondi et al. (2016). The characteristics of the bitumens were evaluated and shown in Table 4.

\section{Experimental work}

\section{Mastic rheological investigation}

\section{Amplitude Sweep test}

Amplitude Sweep tests, according to EN 14470, were preliminarily carried out to investigate the viscoelasticity region at $10^{\circ} \mathrm{C}$ by applying a constant frequency of $10 \mathrm{rad} / \mathrm{s}(1.59 \mathrm{~Hz})$.

\section{Frequency Sweep test}

In order to represent the complex modulus $\left(G^{*}\right)$ and phase angle $(\delta)$ of asphalt mastics, frequency sweep tests according to EN 14470 (Figure 6) were conducted. Master curves were calculated from the tests, finding the relationship between load frequencies and complex modulus $G^{*}$ and phase angle $\delta$. The reference temperature for the master curves was $20^{\circ} \mathrm{C}$. The Williams-LandelFerry model was used to obtain the temperature shift factors. The frequency range was between 0.01 and $10 \mathrm{~Hz}$ from $0{ }^{\circ} \mathrm{C}$ to $60^{\circ} \mathrm{C}$.

\section{Multiple Stress Creep Recovery test}

The Multiple Stress Creep and Recovery test (MSCR) was run according to the AASHTO TP 7007 (2013) "Standard Method of Test for Multiple Stress Creep and Recovery (MSCR) of Asphalt Binders using a Dynamic Shear Rheometer". According to this standard, the mastic sample is loaded at a constant creep stress for $1 \mathrm{~s}$, followed by a zero stress recovery of $9 \mathrm{~s}$. Ten cycles of creep and recovery are run at $0.1 \mathrm{kPa}$ creep stress, followed by 10 at $3.2 \mathrm{kPa}$ creep stress. The non-recoverable compliance $\left(J_{\mathrm{nr}}\right)$ and the percent recovery after 10 cycles at 0.1 and $3.2 \mathrm{kPa}$ were studied. The $J_{\mathrm{nr}}$ value was calculated as the ratio between the average non-recoverable strain for 10 creep and recovery cycles, and the applied stress for those cycles. The testing temperature of $46^{\circ} \mathrm{C}$ was adopted.

\section{Asphalt mixture characterisation}

\section{Volumetric properties}

The $150 \mathrm{~mm}$ diameter specimens were compacted by a gyratory compactor under constant $600 \mathrm{kPa}$ pressure and an external angle of $1.25^{\circ} \mathrm{C}$ for 100 gyrations at $155^{\circ} \mathrm{C}$.

The volumetric characteristics have been determined according to the standard EN 12697-8. In addition to compaction, the curves were analysed to investigate the rate of workability of different mixtures. 


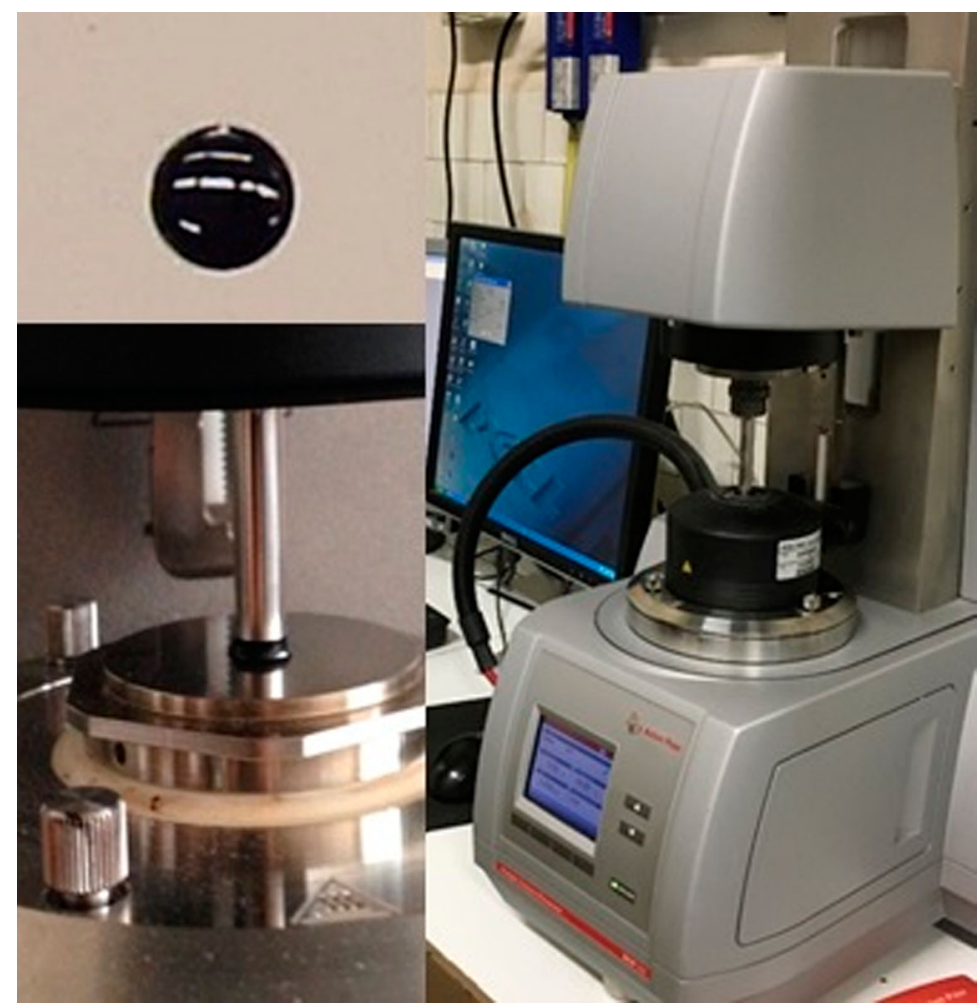

Figure 6. Dynamic Shear Rheometer (Anton Paar MCR302) test set-up and test sample.

Indirect tensile strength

Indirect tensile stiffness modulus. The test was carried out according to $\mathrm{EN} 12697-26$ at $5^{\circ} \mathrm{C}$, $20^{\circ} \mathrm{C}$ and $35^{\circ} \mathrm{C}$. The test has been conducted considering the target of 5 micros train deformation with the standard recommended rise time of $124 \pm 4(\mathrm{~ms})$.

Repeated Load Axial Test. For this research, the test has been conducted following the standard EN $12697-25$ at $40^{\circ} \mathrm{C}$ under the stress level of $100 \mathrm{kPa}$ and all the specimens were subjected to pre-test conditioning loading of $10 \mathrm{~min}$, with the main purpose of ensuring the load platens were seated properly prior to the deformation measurement (Figure 7). In the following, the results are presented in terms of accumulated strain and creep stiffness

$$
E_{n}=\frac{\sigma}{\varepsilon_{n}} \times 1000
$$

where $E_{n}$ is the creep modulus after $n$ load applications, $\sigma$ is the applied stress and $\varepsilon_{n}$ is the cumulative axial strain of the specimen after $n$ load applications (MPa).

\section{Results and discussion}

\section{Effects of GP filler on mastic rheological properties}

Linear visco-elastic field $\left(\gamma_{\mathrm{LVE}}\right)$ of mastic samples is $0.75 \%$ for unmodified bitumen and $0.5 \%$ for SBS-modified bitumen independent of the filler type. The bitumen characteristics have a significant effect on the LVE range, such as the LVE limit deformation of neat bitumen is $50 \%$ 




Figure 7. RLAT configuration.


Figure 8. Master curves comparison: (a) mastic with neat bitumen and (b) mastic with polymer-modified bitumen.

higher than the SBS-modified bitumen (Airey, 1997). From the comparison between master curves of LS-NB and GP-NB mastics (Figure 8(a)), it can be noted that the GP presence tends to increase the mastic stiffness in all frequency range. In particular, this behaviour is enhanced at high and low frequencies. The phase angle behaviour of mastics follows the base bitumen trend; both fillers do not change the visco-elastic response of the bitumen, showing a completely viscous response at high temperature and a predominant elastic response at low temperatures. As shown in Figure 8(b), the SBS presence, in both mastics, is confirmed by the complex modulus increase and phase angle reduction at high temperatures (Airey, 1997). However, in this case, the GP-PmB mastic, containing GP, has higher moduli values than the mastic containing limestone filler at low frequencies, showing the horizontal asymptote in correspondence of the low frequencies. The GP presence increases mastic permanent deformation endurance at high temperatures exalting the polymer effects in terms of shear stress resistance. Moreover, analysing the phase angle trend it can be noticed that the phase angle values of GP-PmB mastic are lower at high temperature compared to the LS-PmB ones. The GP increases the SBS effects in terms of elastic response of the bituminous part.

\section{Effects of GP filler on the asphalt mixture}

Figures 9 and 10 show the compaction curves for the studied mixtures. From the developed compaction curves, it is evident that the slope of the mixtures containing the two investigated 




Figure 9. GP and LS mixtures' compaction curve comparison (neat bitumen).



Figure 10. GP and LS mixtures' compaction curve comparison (polymer-modified bitumen).

Table 5. Volumetric properties of asphalt mixtures.

\begin{tabular}{llll}
\hline Specimen ID & VMA & VA \% & VFA \\
\hline GP-NB & 15.4 & 4.0 & 73.9 \\
LS-NB & 15.7 & 4.4 & 72.3 \\
GP-PmB & 15.9 & 4.6 & 71.3 \\
LS-PmB & 16.6 & 5.40 & 67.3 \\
\hline
\end{tabular}

Note: Gyration number: 100 .

fillers is the same. It can be deduced that the GP filler has no negative effect on the mixture compaction rate (Table 5). Moreover, the mixture containing GP filler has less air voids than mixtures with conventional limestone one, reflecting the results obtained from the Rigden test.

In asphalt mixtures, the mineral skeleton (aggregates) affords the compression strength, and the bitumen and mastic cohesion deliver the tenacity (furthermore the bitumen/aggregates adhesion) (Moreno \& Rubio, 2012). Given that the tensile characteristics of asphalt mixtures are 




Figure 11. The average ITS values at $25^{\circ} \mathrm{C}$.

Table 6. ITSM values in $(\mathrm{MPa})$.

\begin{tabular}{lccccccrr}
\hline & \multicolumn{3}{c}{ Test temperature $\left({ }^{\circ} \mathrm{C}\right)$} & & & \multicolumn{2}{c}{ Test temperature $\left({ }^{\circ} \mathrm{C}\right)$} \\
\cline { 2 - 4 } Spec. ID & 5 & 20 & 35 & & Spec. ID & 5 & 20 & 35 \\
\hline GP-NB & 11,960 & 4638 & 1010 & & LS-NB & 10,188 & 4114 & 1163 \\
GP-NB & 12,743 & 3413 & 816 & & LS-NB & 11,312 & 3090 & 811 \\
GP-NB & 11,996 & 3340 & 966 & LS-NB & 11,543 & 3769 & 957 \\
GP-NB & 11,972 & 3454 & 768 & LS-NB & 11,735 & 3896 & 941 \\
Ave. GP-NB & 12,168 & 3711 & 890 & Ave. LS-NB & 11,194 & 3717 & 968 \\
GP-PmB & 10,469 & 2958 & 750 & LS-PmB & 12,914 & 4031 & 1046 \\
GP-PmB & 9711 & 2102 & 724 & LS-PmB & 12,602 & 4149 & 916 \\
GP-PmB & 15,220 & 4648 & 1479 & LS-PmB & 12,702 & 4055 & 1047 \\
GP-PmB & 13,578 & 3806 & 1011 & LS-PmB & 13,076 & 3941 & 906 \\
Ave. GP-PmB & $12,244.6$ & 3378 & 991 & Ave. LS-PmB & 12,823 & 4044 & 979 \\
\hline
\end{tabular}

indicators of cracking potentiality, it is considered as a fundamental parameter of rutting (Khosla \& Harikrishnan, 2007), thermal and fatigue cracking resistance. In addition, the indirect tensile strength (ITS) value directly depends on the tenacity reached by aggregate/filler and bitumen bonding level (Dondi et al., 2014); hence, the ITS value is considered as a reliable comparative parameter. Figure 11 presents the average values of ITS tests. As expected, the ITS values for the mixtures with PmB are higher than the mixtures with neat bitumen. It can be seen that the test results of mixtures with GP filler are comparable with the ones containing LS filler. In detail, from the result analysis of the mixtures made with unmodified bitumen, it is noted that the presence of GP filler increases the mixture's tenacity. The low viscosity of the unmodified bitumen led to better GP bitumen absorption. On the other hand, for the mixtures made with PmB, the ITS values for control mixture are higher than the mixtures containing GP filler. As found in literature (Ghasemi \& Marandi, 2013), the low bitumen absorption properties of glass increase with higher viscosity bitumen, which leads to lower adhesion properties.

At common traffic flow speeds and pavement temperatures, asphalt mixtures act almost elastically; therefore, indirect tensile stiffness modulus (ITSM) is a measure of its resistance to bending and relatively its loads spreading ability (Nunn \& Smith, 1996). In literature, ITSM is also considered as an indicator for the structural properties of mixtures as it is related to the capacity of mixture to traffic loads bearing (Nassar, Khashaa Mohammed, Thom, \& Parry, 2016). ITSM 




Figure 12. ITSM values.

- GP-PmB $\diamond \quad$ LS-PmB $\quad-\cdots-$ GP-PmB Ave. Trend line $\quad \cdots-\cdot-$ LS-PmB Ave. Trend line

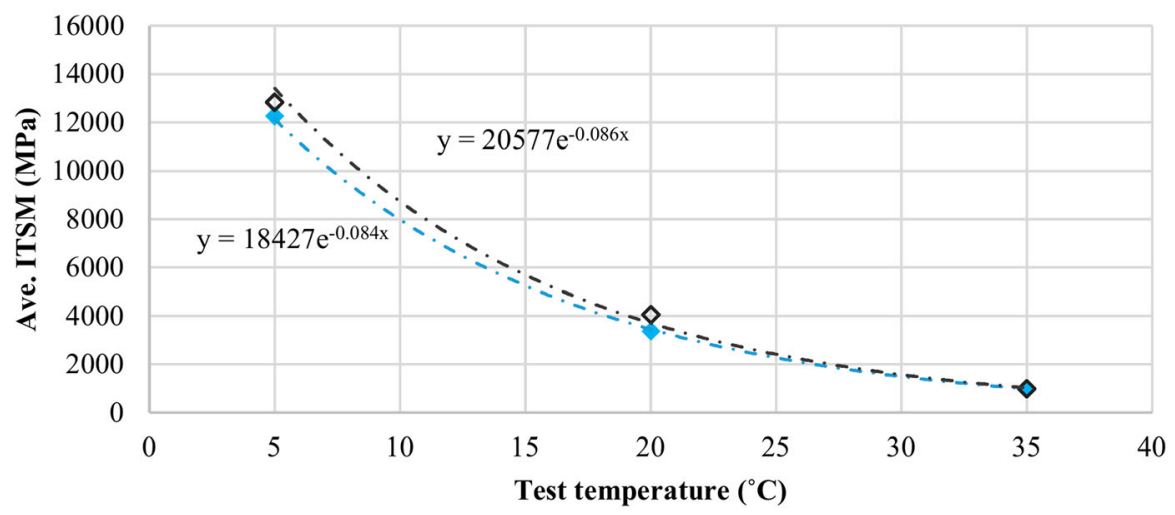

Figure 13. ITSM values.

values greatly depend on test temperature and the results are often considered for thermal sensitivity analysis of asphalt mixtures (Sangiorgi et al., 2016b). From the results showed in Table 6 and Figures 12 and 13, it can be clearly seen that at medium temperatures the difference can be considered negligible as noticed though frequency sweep test results. A discussable difference emerges at low temperatures where, especially in the presence of unmodified bitumen, the higher ITSM values for the mixture with GP filler and neat confirm mastics rheological results. The GP stiffens the bituminous mixtures and increases the bearing capacity.

\section{Permanent deformation evaluation}

\section{Mastic scale permanent deformation susceptibility}

In order to study the rutting resistance of the studied mastics and mixtures, permanent deformation properties were characterised by means of MSCR at $46^{\circ} \mathrm{C}$ and Repeated Load Axial Test (RLAT) at $40^{\circ} \mathrm{C}$, evaluating the probable effect of the GP filler. The standardised temperature was chosen in order to compare these results with RLAT results on asphalt mixture. Figure 14 shows the MSCR curves at the end of the $3.2 \mathrm{kPa}$ shear stress level cycles. Mastics containing GP exhibit stiffer behaviour, accumulating less deformation at the end of the test. The bitumen characteristics of the studied mastics exhibit significantly different response, influencing the glass 




Figure 14. MSCR test result for GP and LS with virgin bituminous mastic at $46^{\circ} \mathrm{C}$ under $0.1 \mathrm{kPa}$ and $3.2 \mathrm{kPa}$.


Figure 15. $J_{\mathrm{nr}}$ values from the MSCR test at $3.2 \mathrm{kPa}$.

powered effects. In the mastics made with the unmodified bitumen, GP filler increased the resistance to deformation during the creep phase but this mastic exhibited a slight recovery during the recovery phase. In contrast, the modified elastomeric bitumens recovered more deformation 




Figure 16. $J_{\mathrm{nr}}$ and accumulated strain correlation.

Table 7. RLA test results at $40^{\circ} \mathrm{C}$.

\begin{tabular}{lcc}
\hline Specimen ID & Accumulated strain (\%) & Creep stiffness MPa \\
\hline GP-NB & 0.886 & 11.42 \\
GP-NB & 0.808 & 13.35 \\
GP-NB & 0.735 & 13.72 \\
Ave. GP-NB & 0.810 & 12.83 \\
LS-NB & 0.739 & 13.51 \\
LS-NB & 1.178 & 8.57 \\
LS-NB & 0.808 & 12.35 \\
Ave. LS-NB & 0.908 & 11.48 \\
GP-PmB & 0.738 & 13.52 \\
GP-PmB & 0.612 & 16.31 \\
GP-PmB & 0.645 & 15.57 \\
Ave. GP-PmB & 0.665 & 15.13 \\
LS-PmB & 0.851 & 11.60 \\
LS-PmB & 0.699 & 14.23 \\
LS-PmB & 0.737 & 13.52 \\
Ave. LS-PmB & 0.762 & 13.12 \\
\hline
\end{tabular}

during the unload phase. Polymer-modified bituminous mastic has significantly higher capacity of recoverable strain and, as confirmed by the FS sweep test analysis, the GP presence exalts this characteristic. At both shear stress levels, the GP-PmB exhibits lower values of accumulated strain than the mastic containing limestone filler.

The results of MSCR curves are confirmed studying the non-recoverable compliance values (Figure 15). $J_{\mathrm{nr}}$ values were calculated for the four mastics under $3.2 \mathrm{kPa}$ shear stresses at $46^{\circ} \mathrm{C}$. The GP mastics, obtained with both unmodified and modified bitumen, have lower values of non-recoverable compliance at $3.2 \mathrm{kPa}$, showing less sensitivity to permanent deformations.

\section{Asphalt mixture permanent deformation susceptibility}

In the current study, the direct uniaxial cyclic compression configuration, termed the permanent deformation properties was followed by applying RLAT. From the results presented in Table 7, the mixtures containing GP filler show less accumulated strain values and higher creep stiffness 
moduli if compared to the mixtures containing the traditional limestone filler. From the results provided by the RLAT test, in accordance with the studies conducted by Khosla and Harikrishnan (2007), GP filler was found to increase surface layer resistance to permanent deformations. This analysis has been thoroughly investigated correlating the mixture response to RLAT load to that of the mastic during the MSCR test. Based on the correlation between ALF rutting parameter and $J_{\mathrm{nr}}$ extracted by D'Angelo, Kluttz, Dongré, Stephens, and Zanzotto (2007), a correspondence between the accumulated strain and $J_{\mathrm{nr}}$ has been extrapolated (Figure 16). As found in the cited studies, also in this case the coefficient of determination is greater than 0.8 confirming how the rheological results, obtained through the MSCR test, can be related to mixture performances. From the permanent deformation evaluation, it is clear that the stiffness increase given by the GP filler is reflected on the resistance to rutting phenomena.

\section{Conclusions}

The present research confirmed the applicability of reusing fine GP as a filler with both neat and modified binders. The main purpose of this research was to characterise the GP as a suitable material for the road pavements construction, replacing with traditional limestone filler. The multi-scale approach has been validated within the consistent results obtained from both the rheological and mixture analysis results. In detail, both ITSM and RLAT results reflected the FS and MSCR data relating mastic rutting performance to in service pavements. The use of GP as a filler in the asphalt mixtures follows the GPP criteria in terms of recovery and reuse of a waste material for the main road elements. As part of the infrastructures, LCA future studies will involve the evaluation of mixture durability in term of fatigue life and energy savings achieved through the use of GP.

The results obtained from the physical characterisation confirmed the suitability of GP to use as filler. In terms of interaction between unmodified and modified bitumen with GP, the rheological properties of mastics were studied. From the results obtained by performing FS and MSCR tests, the GP filler increases the mastic stiffness and at the same time exalts SBS polymer modification in terms of elastic shear stress response. From the mixture point of view, the ITSM and RLAT results indicated that the GP filler could provide to improve mixtures performance in terms of bearing capacity and permanent deformations resistance.

\section{Disclosure statement}

No potential conflict of interest was reported by the authors.

\section{References}

Airey, G. D. (1997). Rheological characteristics of polymer modified and aged bitumens (Ph.D. Thesis). Department of Civil Engineering, University of Nottingham, UK.

Al-Hdabi, A. (2016). Laboratory investigation on the properties of asphalt concrete mixture with rice husk ash as filler. Construction and Building Materials. doi:10.1016/j.conbuildmat.2016.09.070

Anderson, D. A., Le Hir, Y. M., Marasteanu, M. O., Planche, J. P., Martin, D., \& Gauthier, G. (2001). Evaluation of fatigue criteria for asphalt binders (pp. 48-55). Transportation Research Record 1766. Washington, DC: Transportation Research Board. doi:10.3141/1766-07

Arabani, M., Tahami, S. A., \& Taghipoor, M. (2016). Laboratory investigation of hot mix asphalt containing waste materials. Road Materials and Pavement Design. doi:10.1080/14680629.2016.1189349

D’Angelo, J., Kluttz, R., Dongré, R., Stephens, K., \& Zanzotto, L. (2007). Revision of the superpave high temperature binder specification: The multiple stress creep recovery test. Asphalt Paving Technology, 76(123), 123-162. 
Dondi, G., Mazzotta, F., Sangiorgi, C., Pettinari, M., Simone, A., Vignali, V., \& Tataranni, P. (2014). Influence of cement and limestone filler on the rheological properties of mastic in cold bituminous recycled mixtures. In Proceeding of 3rd international conference on transportation infrastructures-ICTI 2014 , April 22-25, Pisa, Italy.

Dondi, G., Mazzotta, F., Simone, A., Vignali, V., Sangiorgi, C., \& Lantieri, C. (2016). Evaluation of different short term aging procedures with neat, warm and modified binders. Construction and Building Materials. doi:10.1016/j.conbuildmat.2015.12.122

Flynn, L. (1993). Glasphalt utilization dependent on availability. Road and Bridge, 31(2), 59-61.

Ghasemi, M., \& Marandi, S. M. (2013). Laboratory studies of the effect of recycled glass powder additive on the properties of polymer modified asphalt binders. International Journal of Engineering. doi:10.5829/idosi.ije.2013.26.10a.08

Jony, H. H., Al-Rubaie, M. F., \& Jahad, I. Y. (2011). The effect of using glass powder filler on Hot asphalt concrete mixtures properties. Engineering \& Technologies Journal, 29(1), 44-57.

Kandhal, P. S. (1996). Waste materials in hot mix asphalt-An overview. NCAT Report 92-06.

Khosla, N., \& Harikrishnan, K. I. (2007). Tensile strength - A design and evaluation tool for Superpave mixtures. FHWA/NC/2006-24 Final report.

Kim, Y. R., Allen, D. H., \& Little, D. N. (2007). Computational constitutive model for predicting nonlinear viscoelastic damage and fracture failure of asphalt concrete mixtures. International Journal of Geomechanics, 7(2), 102-110. doi:10.1061/(ASCE)1532-3641(2007)7:2(102)

Lamperti, R., Grenfell, J., Sangiorgi, C., Lantieri, C., \& Airey, G. D. (2016). Influence of waxes on adhesion properties of bituminous binders. Construction and Building Materials. doi:10.1016/ j.conbuildmat.2014.11.058

Mazzotta, F., Lantieri, C., Vignali, V., Simone, A., Dondi, G., \& Sangiorgi, C. (2017). Performance evaluation of recycled rubber waterproofing bituminous membranes for concrete bridge decks and other surfaces. Construction and Building Materials. doi:10.1016/j.conbuildmat.2017.01.058

Mazzotta, F., Sangiorgi, C., Vignali, V., Lantieri, C., \& Dondi, G. (2015). Rheological characterization of bituminous mastics containing waste bleaching clays. RILEM Bookseries. doi:10.1007/ 978-94-017-7342-3_48

Moreno, N. F., \& Rubio, G. M. C. (2012). Influence of crumb rubber on the indirect tensile strength and stiffness modulus of hot bituminous mixes. Journal of Materials in Civil Engineering. doi:10.1061/(ASCE)MT.1943-5533.0000436

Nassar, A. I., Khashaa Mohammed, M., Thom, N., \& Parry, T. (2016). Characterization of high-performance cold bitumen emulsion mixtures for surface courses. International Journal of Pavement Engineering. doi:10.1080/10298436.2016.1176165

Nunn M. E., \& Smith, T. M. (1996). The indirect tensile stiffness modulus test: Assessment of suitability of an asphalt performance test. TRL Proj. Rep. CE/140/96, UK.

Saffar, N. A. L. (2013). The effect of filler type and content on hot asphalt concrete mixtures properties. Al-Rafidain Engineering, 21(6), 88-100.

Sangiorgi, C., Eskandarsefat, S., Tataranni, P., Simone, A., Vignali, V., Lantieri, C., \& Dondi, G. (2016a). A complete laboratory assessment of crumb rubber porous asphalt. Construction and Building Materials. doi:10.1016/j.conbuildmat.2016.12.016

Sangiorgi, C., Tataranni, P., Mazzotta, F., Simone, A., Vignali, V., \& Lantieri, C. (2017). Alternative fillers for the production of bituminous mixtures: A screening investigation on waste powders. MDPI Coatings, 7(6), 76. doi:10.3390/coatings7060076

Sangiorgi, C., Tataranni, P., Simone, A., Vignali, V., Lantieri, C., \& Dondi, G. (2016b). Assessment of waste bleaching clay as alternative filler for the production of porous asphalts. Construction and Building Materials. doi:10.1016/j.conbuildmat.2016.01.052

Tang, B., Wu, H., Liao, Y., \& Huang, D. (2015). Effect of glass powder instead of mineral powder on asphalt mixture. 5th international conference on civil engineering and transportation, ICCET.

Udaya, B. V., \& Venkateswara, R. J. (2016). Influence of glass powder and quartzite rock dust as fillers in stone mastic asphalt. International Journal of Engineering Research \& Technology (IJERT). doi:10.17577/IJERTV5IS110118

Vignali, V., Mazzotta, F., Sangiorgi, C., Simone, A., Lantieri, C., \& Dondi, G. (2016). Incorporation of rubber powder as filler in a new dry-hybrid technology: Rheological and 3D DEM mastic performances evaluation. Materials. doi:10.3390/ma9100842

Wu, S., Yang, W., \& Xue, Y. (2007). Preparation and properties of glass-asphalt concrete. Wuham University of Technology: Key Laboratory for Silicate Materials Science and Engineering of Ministry of Education. 